\title{
STUDI DEBIT ANGKUTAN SEDIMEN DASAR SUNGAI CITARUM DENGAN RUMUS EINTEIN'S, SHIELDS, SCHOKLITSCH'S DAN LABORATORIUM
}

\author{
Marvin $^{1}$ dan Wati A. Pranoto ${ }^{2}$ \\ ${ }^{1}$ Program Studi Sarjana Teknik Sipil, Universitas Tarumanagara, Jl. Letjen S. Parman No.1 Jakarta \\ Email: marvinsubari21@gmail.com \\ 2Program Studi Magister Teknik Sipil, Universitas Tarumanagara, Jl. Letjen S. Parman No.1 Jakarta \\ Email:watip@ft.untar.ac.id
}

\begin{abstract}
ABSTRAK
Sungai Citarum merupakan salah satu sungai terpanjang di provinsi Jawa Barat dengan panjang 297 $\mathrm{km}$. Sungai Citarum tidak hanya mengalirkan air, tetapi juga membawa sedimen yang berasal dari hasil erosi. Sampel yang digunakan untuk penelitian ini diambil di muara Ci-Beet. Penelitian ini dilakukan di laboratorium Mekanika Tanah dan laboratorium Hidrolika dengan menggunakan sirkular flum, dilakukan dengan menggunakan 3 tabung sampel dan di tes dengan berbagai kecepatan. Penelitian ini difokuskan pada angkutan sedimen dasar (bed-load) dan dibandingkan antara hasil laboratorium dengan 3 pendekatan yaitu Einstein's, Shields, dan Schoklitsch's. Untuk debit air 0,0024 - 0,0035 $\mathrm{m}^{3} / \mathrm{s}$, angkutan sedimen dasar yang didapat di laboratorium $0,0026-0,0557 \mathrm{~kg} / \mathrm{s} / \mathrm{m}$, pendekatan Einstein's sebesar 0,0175 kg/s/m, pendekatan Shields $0,0211-0,031 \mathrm{~kg} / \mathrm{s} / \mathrm{m}$, dan pendekatan Schoklitsch's 0,0065 - 0,0099 kg/s/m. Dari ke-3 pendekatan itu didapat bahwa pendekatan Shields yang paling baik untuk digunakan.
\end{abstract}

Kata kunci: angkutan sedimen dasar, sungai Citarum, percobaan laboratorium, debit.

\section{PENDAHULUAN}

\section{Latar belakang}

Sungai Citarum merupakan salah satu sungai di Indonesia, dengan panjang sungai utama $297 \mathrm{~km}$, sungai Citarum menjadi sungai terbesar dan terpanjang di Provinsi Jawa Barat. Wilayah sungai Citarum merupakan Wilayah Sungai Strategis Nasional menurut Permen PUPR no. 04 Tahun 2015. Luas wilayah sungai Citarum mencapai 1.132.334 Ha.

Sungai Citarum memiliki 19 daerah aliran sungai (DAS), meliputi 10 kabupaten dan 2 kota. Berawal dari mata air yang terletak di Gunung Wayang (Kabupaten Bandung) lalu berakhir di daerah Muara Gembong dengan melewati Kabupaten Bandung/Bandung Barat, Kabupaten Cianjur, Kabupaten Purwakarta, dan Kabupaten Karawang/Bekasi (BBWS Citarum, 2016).

Air yang mengalir pada sungai Citarum selain membawa air, sungai ini juga membawa berbagai macam partikel. Partikel yang terbawa aliran air ini akibat dari erosi yang terjadi pada sungai ini dan daerah aliran sungai. Setelah itu partikel ini dapat mengendap di beberapa bagian sungai karena proses sedimentasi.

Dalam proses sedimentasi, ada banyak faktor yang mempengaruhi transport sedimen. Selain dipengaruhi kecepatan aliran, angkutan sedimen dasar (Bed Load Transport) dipengaruhi juga oleh panjang sungai, kemiringan dasar sungai, penampang sungai, dan berbagai parameter lainnya yang mempengaruhi proses sedimentasi.

Banyak pendekatan yang digunakan para ahli untuk meneliti dan mengembangkan studi mengenai angkutan sedimen dasar (Bed Load Transport). Penelitian dilakukan untuk membandingkan hasil di laboratorium dengan hasil pendekatan yang dikemukakan oleh beberapa ahli. Pendekatan yang dikemukakan diantaranya (Yang, 1996) :

1. Shear stress approach yang dikemukakan oleh Duboys (1879) dan Shield (1936)

2. Discharge approach yang dikembangkan oleh Schoklitsch $(1934,1943)$

3. Probabilistic approach yang dikembangkan oleh Einstein $(1942,1950)$ dan Brown (1950) 


\section{Batasan masalah}

Dalam penelitian ini, batasan-batasan yang digunakan sebagai berikut:

1. Analisa hanya dilakukan pada sampel sedimen kasar Sungai Citarum.

2. Analisa dilaksanakan di laboratorium Mekanika Tanah dan laboratorium Hidrolika.

3. Analisa dilaksanakan di laboratorium dan dengan 3 pendekatan yaitu Einstein's, Shields, dan Schoklitsch's.

\section{Rumusan masalah}

Rumusan masalah yang akan dibahas pada penelitian ini:

1. Bagaimana hasil debit angkutan sedimen dasar dari pendekatan Einstein's, Shields, dan Schoklitsch's?

2. Bagaimana hasil angkutan sedimen dasar dengan variasi kecepatan pada studi laboratorium?

3. Bagaimana perbandingan hasil laboratorium dan hasil pendekatan rumus?

\section{Tujuan penelitian}

Beberapa tujuan dari penelitian ini adalah:

1. Untuk memperoleh nilai debit angkutan sedimen dasar $\left(q_{b}\right)$ dari pendekatan Einstein's, Shields, dan Schoklitsch's.

2. Untuk mendapatkan nilai angkutan sedimen dasar dengan beberapa variasi kecepatan.

3. Untuk memperoleh perbandingan nilai debit angkutan sedimen dasar dari hasil laboratorium dan hasil pendekatan rumus.

\section{TINJAUAN PUSTAKA}

\section{Angkutan Sedimen Dasar (Bed Load Transport)}

Ketika aliran air memenuhi atau melampaui kriteria untuk terjadinya gerakan pada lapisan dasar, maka partikel sedimen yang berupa partikel tanah akan mulai bergerak terbawa oleh aliran air. Jika selama sedimen menyentuh dasar sungai, ini disebut angkutan sedimen dasar (bed load transport). Secara umum, rata-rata angkutan sedimen dasar di sungai berkisar antara 5-25\% dari total aliran. Namun material sedimen yang kasar akan lebih tinggi persentase kemungkinan terbawa oleh aliran sebagai angkutan sedimen dasar.

$$
\begin{gathered}
Q_{\text {air }}=v \times B \times H \\
Q_{b}=Q_{\text {air }} \times(C s: 1000: B)
\end{gathered}
$$

Dengan Cs = konsentrasi sedimen $(\mathrm{ppm}), \mathrm{Q}_{\text {air }}=$ debit air $\left(\mathrm{m}^{3} / \mathrm{s}\right), \mathrm{v}=$ kecepatan air $(\mathrm{m} / \mathrm{s}), \mathrm{B}=$ lebar saluran $(\mathrm{m}), \mathrm{H}=$ tinggi air $(\mathrm{m}), \mathrm{Q}_{\mathrm{b}}=$ debit angkutan sedimen dasar $(\mathrm{kg} / \mathrm{s} / \mathrm{m})$.

\section{Persamaan Angkutan Sedimen Dasar (Bed Load Transport)}

Pendekatan rumus empiris yang dikembangkan oleh para ahli tentang angkutan sedimen dasar, tentu mempunyai batasan masing-masing. Pada penelitian ini, digunakan 3 rumus yaitu Einstein's, Shields, dan Schoklitsch. Pada rumus Einstein's hanya menggunakan diameter partikel, sedangkan Shields menggunakan tegangan geser, dan Schoklitsch menggunakan debit untuk mencari angkutan sedimen dasar. (Sengupta, 1994)

Einstein's merumuskan angkutan sedimen dasar dengan menggunakan persamaan

$$
\boldsymbol{\Phi}=\frac{q_{b}}{\gamma_{s}}\left(\frac{\gamma}{\gamma_{s}-\gamma} \boldsymbol{x} \frac{1}{g D^{3}}\right)^{1 / 2}
$$

Shields merumuskan angkutan sedimen dasar dengan menggunakan persamaan

$$
\frac{q_{b} \gamma_{s}}{q S \gamma}=\frac{10\left(\tau-\tau_{c}\right)}{\left(\gamma_{S}-\gamma\right) d_{50}}
$$

Schoklitsch's merumuskan angkutan sedimen dasar dengan menggunakan persamaan

$$
Q_{b}=7000 \frac{s^{3 / 2}}{d^{1 / 2}}\left(q-q_{c}\right)
$$


dengan $\Phi=$ parameter intensitas bed load, $\gamma$ dan $\gamma_{\mathrm{s}}=$ Berat jenis air dan berat jenis sedimen $\left(\mathrm{kg} / \mathrm{m}^{2}\right), \mathrm{D}=\operatorname{diameter}$ sedimen $(\mathrm{m}), \mathrm{S}=$ kemiringan tanah, $\mathrm{q}=$ debit air $\left(\left(\mathrm{m}^{3} / \mathrm{s}\right) / \mathrm{m}\right), \mathrm{q}_{\mathrm{c}}=$ debit kritis air saat terjadi gerak awal $\left(\left(\mathrm{m}^{3} / \mathrm{s}\right) / \mathrm{m}\right)$.

Nilai $\Phi$ diperoleh dari grafik perbandingan pada Gambar 1

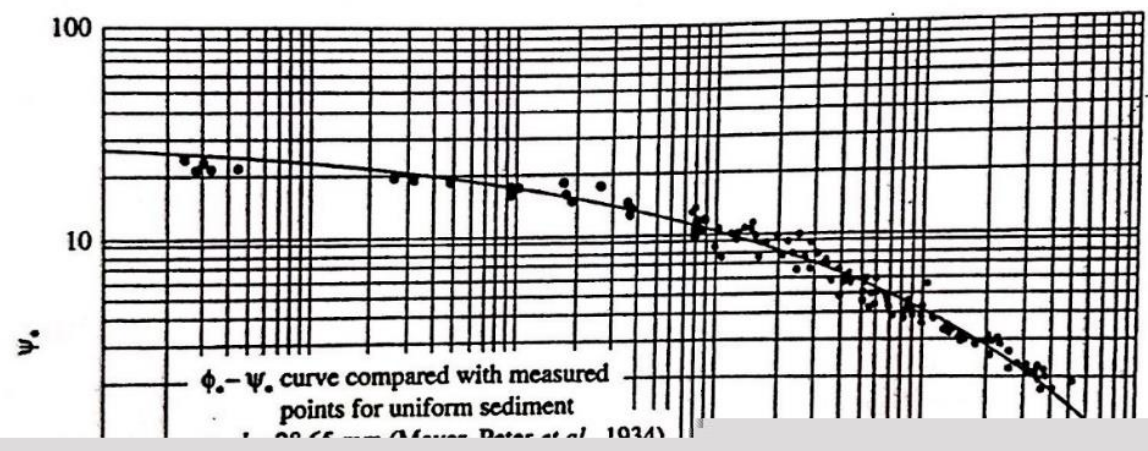

Gambar 1. Parameter Intensitas Aliran Terhadap Intensitas Bed Load (Chih Ted Yang, 1996)

Nilai C (dimensionless shear stress) didapat dari Gambar 2.

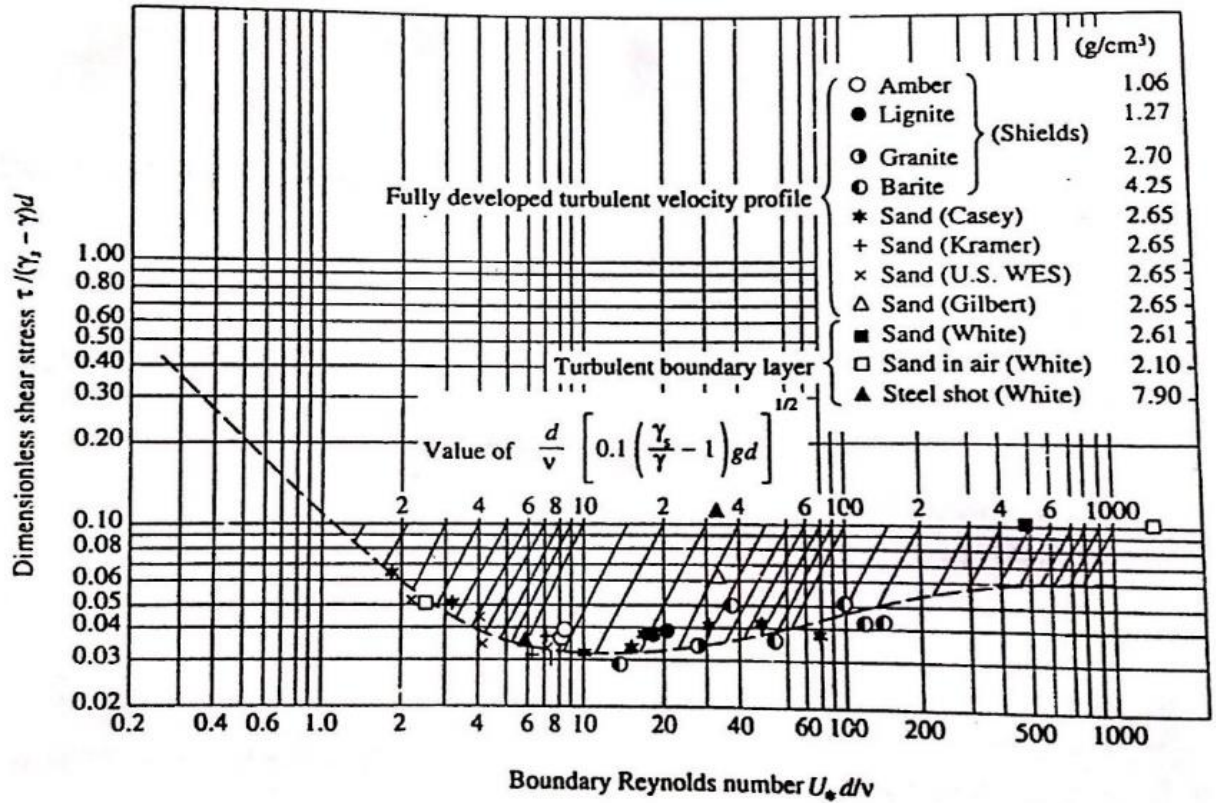

Gambar 2. Diagram Shields (Dake,M. K Jones, 1985 Dalam buku Chih Ted Yang, 1996) 


\section{METODOLOGI PENELITIAN}

\section{Metode Analisis Data}

Sebelum dilakukannya analisis data, dilakukan pembelajaran atau studi tentang teori-teori dasar yang berhubungan dengan topik pembahasan dalam penelitian yang akan dilakukan. Teori dasar yang digunakan sebagai acuan pembelajaran dapat dicari berdasarkan berbagai macam sumber, seperti jurnal, karya ilmiah, buku referensi. Setelah memahami mengenai penelitian ini, dilakukan persiapan sampel lalu melakukan percobaan laboratorium. Kemudian hasil yang didapat dari percobaan laboratorium dibandingkan dengan ketiga pendekatan yaitu pendekatan Einstein's, Shields, dan Schoklitsch's.

\section{ANALISIS DAN PEMBAHASAN}

\section{Sieve Analysis}

Dalam penelitian ini dilakukan percobaan di laboratorium mekanika tanah untuk mengetahui jenis tanah yang digunakan sebagai sampel pada penelitian ini dan data hasil pengujian laboratorium tersaji dalam Tabel 1.

Tabel 1. Resume Sieve Analysis

\begin{tabular}{ccccc}
\hline Sieve No 1 & Diam. (mm) & Wt. retained & \% reatained & \% passsing \\
\hline 4 & 4.75 & 0.4 & 0.08 & 99.92 \\
\hline 10 & 2 & 6.7 & 1.34 & 98.58 \\
\hline 20 & 0.85 & 21.6 & 4.32 & 94.26 \\
\hline 40 & 0.425 & 110.7 & 22.14 & 72.12 \\
\hline 60 & 0.25 & 229.7 & 45.94 & 26.18 \\
\hline 140 & 0.106 & 40.5 & 8.1 & 18.08 \\
\hline 200 & 0.075 & 0.2 & 0.04 & 18.04 \\
\hline pan & - & 0.3 & 0.06 & \\
\hline sum & & 410.1 & & \\
\hline
\end{tabular}

Dalam Tabel 1. dapat mengetahui ukuran butiran yang paling mendominasi pada sampel yang akan digunakan adalah ukuran diameter $0.25 \mathrm{~mm}$.

\section{Percobaan laboratorium Hidrolika Hasil Percobaan Berdasarkan Kedalaman}

Rangkuman hasil uji laboratorium hidrolika berdasarkan kedalaman dapat dilihat pada Tabel 2, Tabel 3 dan Tabel 4.

Tabel 2. Rekapitulasi Kecepatan Kritis

\begin{tabular}{ccccc}
\hline \multirow{2}{*}{$\begin{array}{c}\text { Kedalaman } \\
\text { sampel } \\
(\mathrm{cm})\end{array}$} & $1(\mathrm{~m} / \mathrm{s})$ & $2(\mathrm{~m} / \mathrm{s})$ & $3(\mathrm{~m} / \mathrm{s})$ & Rata-rata \\
\cline { 2 - 5 } & 0,10977 & 0,10394 & 0,11315 & 0,10895 \\
\hline 0 & 0,128 & 0,12537 & 0,13928 & 0,13089 \\
\hline-3 & 0,1688 & 0,12706 & 0,13421 & 0,14336 \\
\hline-6 & 0,16936 & 0,13947 & 0,14323 & 0,15069 \\
\hline-9 & 0,18422 & 0,15508 & 0,15056 & 0,16329 \\
\hline-12 & & & &
\end{tabular}


Tabel 3. Rekapitulasi Berat Jenis Basah

\begin{tabular}{ccccc}
\hline $\begin{array}{c}\text { Kedalaman } \\
\text { sampel } \\
(\mathrm{cm})\end{array}$ & $\begin{array}{c}1 \\
\left(\mathrm{~g} / \mathrm{cm}^{3}\right)\end{array}$ & $\begin{array}{c}2 \\
\left(\mathrm{~g} / \mathrm{cm}^{3}\right)\end{array}$ & $\begin{array}{c}3 \\
\left(\mathrm{~g} / \mathrm{cm}^{3}\right)\end{array}$ & Rata-rata \\
\hline 0 & 1,44559 & 1,66419 & 1,55892 & 1,55623 \\
\hline-3 & 1,48135 & 1,70309 & 1,64959 & 1,61134 \\
\hline-6 & 1,54784 & 1,66077 & 1,6529 & 1,6205 \\
\hline-9 & 1,56152 & 1,66042 & 1,6561 & 1,62603 \\
\hline-12 & 1,61268 & 1,66638 & 1,6835 & 1,65419 \\
\hline
\end{tabular}

Tabel 4. Rekapitulasi Berat Jenis Kering

\begin{tabular}{ccccc}
\hline \multirow{2}{*}{$\begin{array}{c}\text { Kedalaman } \\
\text { sampel } \\
(\mathrm{cm})\end{array}$} & $\begin{array}{c}1 \\
\left(\mathrm{~g} / \mathrm{cm}^{3}\right)\end{array}$ & $\begin{array}{c}2 \\
\left(\mathrm{~g} / \mathrm{cm}^{3}\right)\end{array}$ & $\begin{array}{c}3 \\
\left(\mathrm{~g} / \mathrm{cm}^{3}\right)\end{array}$ & Rata-rata \\
\hline 0 & 1,09843 & 1,19932 & 1,17080 & 1,15618 \\
\hline-3 & 1,14603 & 1,22576 & 1,19838 & 1,19006 \\
\hline-6 & 1,15243 & 1,19747 & 1,19211 & 1,18067 \\
\hline-9 & 1,16150 & 1,17347 & 1,19730 & 1,17742 \\
\hline-12 & 1,18709 & 1,19920 & 1,21170 & 1,19933 \\
\hline
\end{tabular}

\section{Analisis Debit Angkutan Sedimen Berdasarkan Hasil Laboratorium}

Rangkuman hasil analisa debit angkutan sedimen dasar dari hasil percobaan laboratorium dapat dilihat pada Gambar 3 .

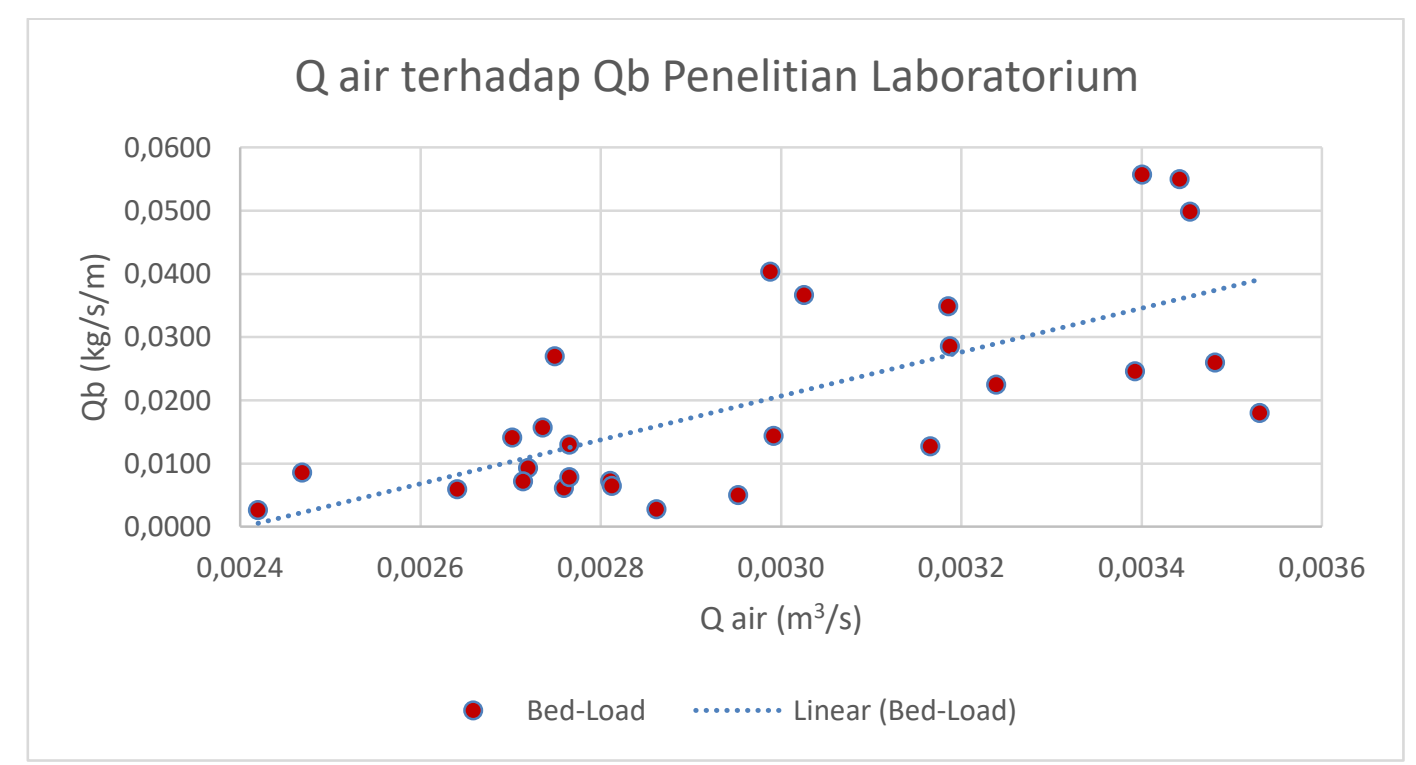

Gambar 3. Grafik Perbandingan Debit Air Terhadap Debit Angkutan Sedimen Dasar 
Studi Debit Angkutan Sedimen Dasar Sungai Citarum dengan Rumus Einstein's, Shields, Schoklitsch's dan Laboratorium

\section{Analisis Debit Angkutan Sedimen Berdasarkan Pendekatan Einstein's}

Hasil analisa debit angkutan sedimen dasar dari Pendekatan Einstein's dapat dilihat pada Gambar 4.

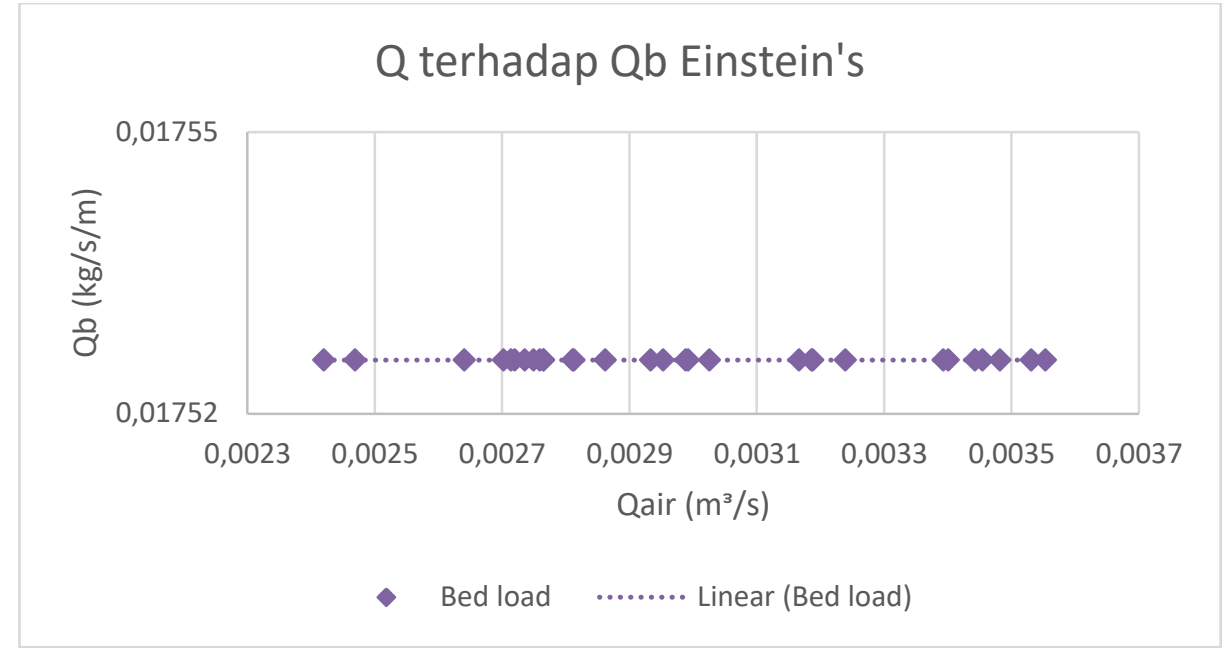

Gambar 4. Grafik Debit Air Terhadap Debit Angkutan Sedimen Dasar Einstein’s

\section{Analisis Debit Angkutan Sedimen Berdasarkan Pendekatan Shields}

Hasil analisa debit angkutan sedimen dasar dari Pendekatan Shields dapat dilihat pada Gambar 5.

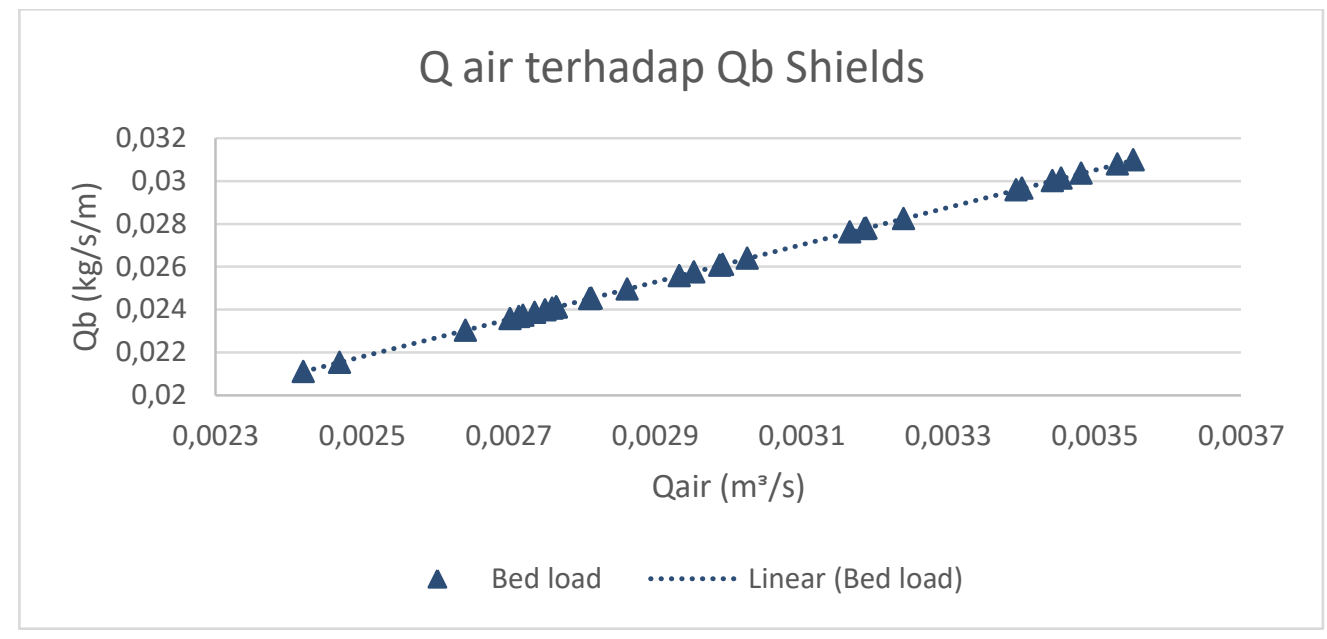

Gambar 5. Grafik Debit Air Terhadap Debit Angkutan Sedimen Dasar Shields 


\section{Analisis Debit Angkutan Sedimen Berdasarkan Pendekatan Schoklitsch's}

Hasil analisa debit angkutan sedimen dasar dari Pendekatan Schoklitsch dapat dilihat pada Gambar 6.

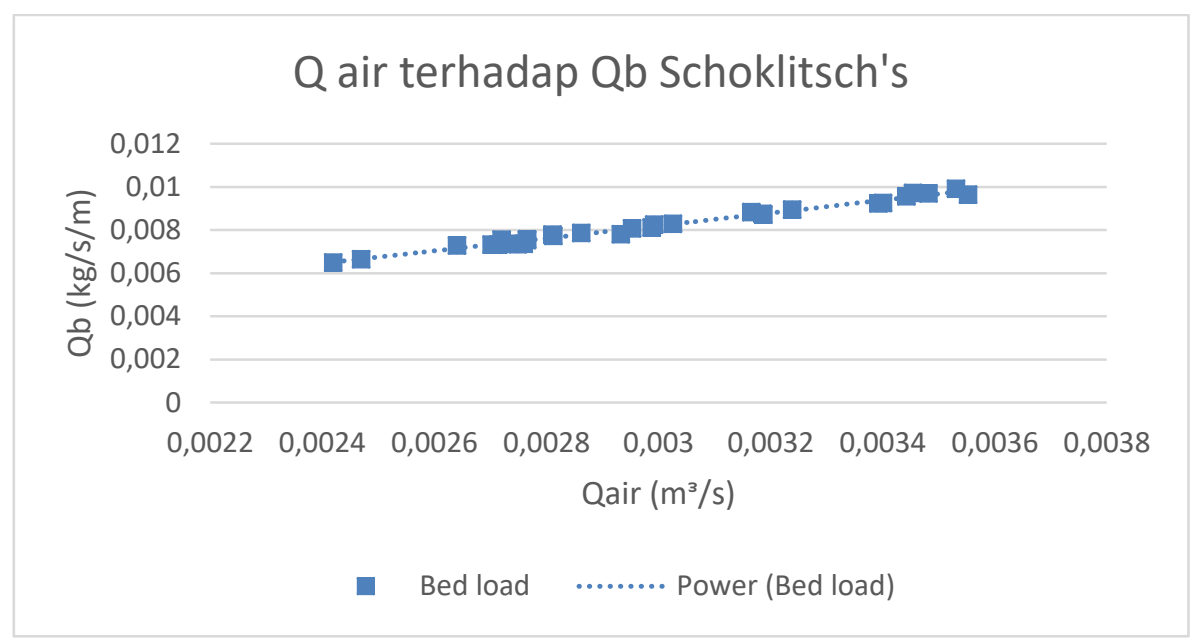

Gambar 6. Grafik Debit Air Terhadap Debit Angkutan Sedimen Dasar Einstein's

\section{Perbandingan Hasil Laboratorium Dengan Pendekatan Rumus}

Rangkuman perbandingan hasil penelitian laboratorium dengan hasil pendekatan rumus dapat dilihat pada Gambar 7.

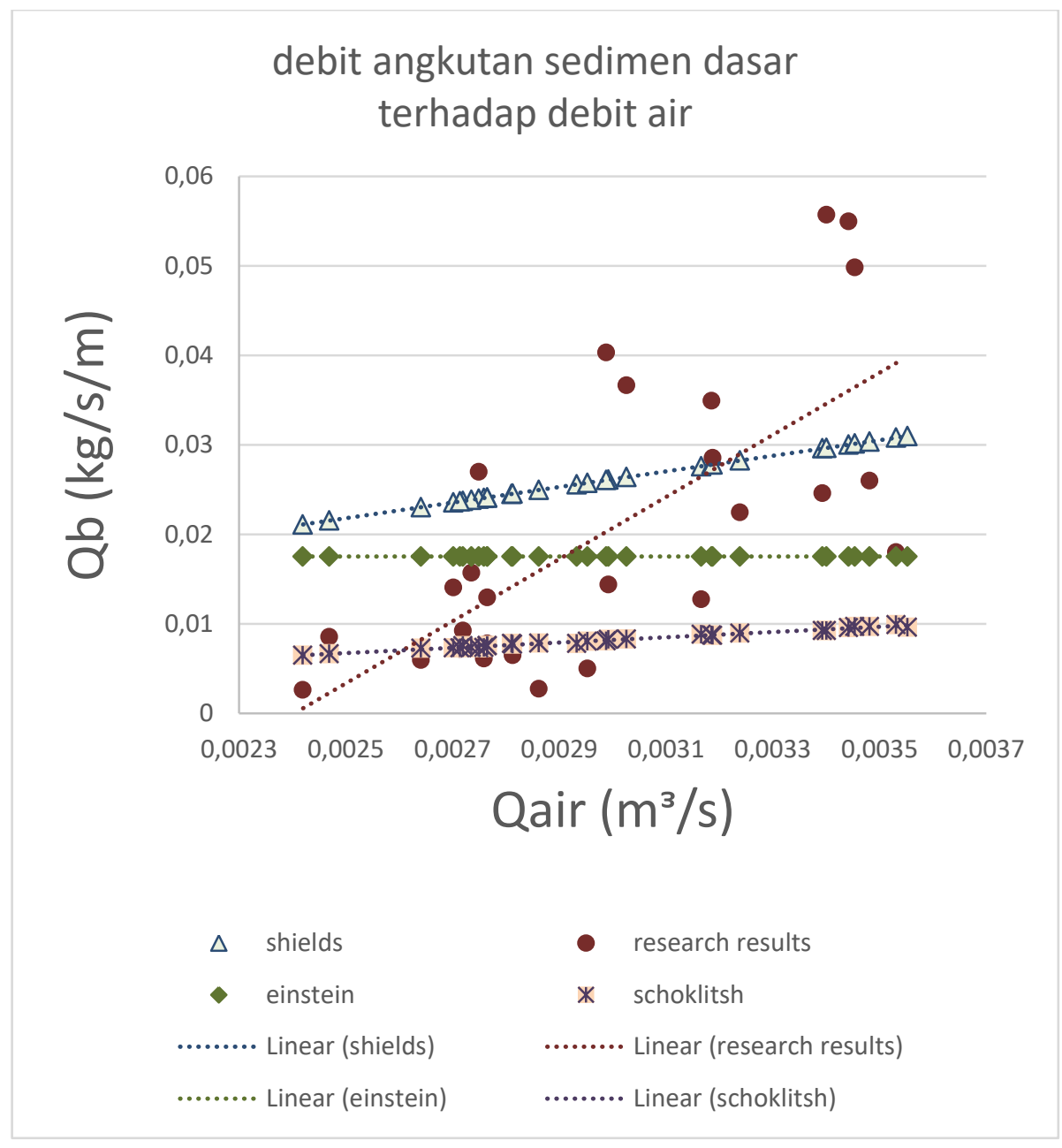

Gambar 7. Grafik Perbandingan Debit Angkutan Sedimen Dasar 


\section{KESIMPULAN}

Berdasarkan analisis yang dilakukan, didapatkan beberapa kesimpulan sebagai berikut:

1. Gradasi butiran sedimen Sungai Citarum yang paling banyak berkontribusi pada ukuran diameter 0,25 mm (sieve No.60).

2. Kedalaman lapisan sedimen mempengaruhi kecepatan kritis, berat jenis basah, dan berat jenis kering. Semakin bertambahnya kedalaman maka kecepatan kritis yang dibutuhkan juga semakin besar. Semakin bertambahnya kedalaman maka berat jenis basah dan berat jenis kering yang dihasilkan semakin besar.

3. Hasil penelitian ini, rumus Schoklitsch's dapat digunakan pada debit air antara $0,0024-0,0029 \mathrm{~m}^{3} / \mathrm{s}$, rumus Einsteins's dapat digunakan pada debit air antara $0,0029-0,0033 \mathrm{~m}^{3} / \mathrm{s}$, dan rumus Shields dapat digunakan pada debit air $>0,0033 \mathrm{~m}^{3} / \mathrm{s}$.

4. Perbedaan tersebut berasal dari pendekatan masing-masing rumus yang berbeda, dimana pada rumus Schoklitsch's menggunakan pendekatan debit (discharge approach), rumus Einstein's tidak memperhitungkan kecepatan aliran dengan asumsi erosi dan pengendapan yang terjadi kecil, dan rumus Shields menggunakan pendekatan tegangan geser (shear stress approach).

5. Besaran debit dalam penelitian $0,0024-0,0035 \mathrm{~m}^{3} / \mathrm{s}$ dan debit angkutan sedimen dasar sungai Citarum yang diperoleh $0,0026-0,0557 \mathrm{~kg} / \mathrm{s} / \mathrm{m}$.

\section{DAFTAR PUSTAKA}

Balai Besar Wilayah Sungai Citarum. 2016. Paparan TKPSDA WS Citarum 20 april 2016.

Sengupta S. 1994. Introduction to Sedimentology. Indian Institute of Technology Kharagpur. India.

Yang, C.T. 1996. Sediment Transport Teory and Practice. The MacGraw Companies. United States of America. 